\title{
EDITORIAL \\ Health care reform and the uninsured: lessons from Massachusetts
}

\author{
Bob S. Carter, MD, PhD, ${ }^{1}$ and David C. Chang, PhD, MPH, MBA ${ }^{2}$ \\ 'Department of Neurosurgery, UC San Diego, California; and 2Department of Surgery, Massachusetts General Hospital, \\ Boston, Massachusetts
}

$\mathrm{I}$ $\mathrm{N}$ their paper, Villelli et al. have characterized the impact of the Massachusetts health care reform that was passed in 2006, which has been widely regarded as a precursor to the national Affordable Care Act (ACA) reform passed in 2010. ${ }^{3}$ Using two large state databases from Massachusetts and New York, the authors contrast the impact of health care reform legislation on total volume of neurosurgical procedures and insurance trends for shunt, cranial tumor, other cranial and vascular, and spine cases from 2001 to 2012.

First, we would like to make an observation about the insurance status of patients in these two states: both Massachusetts and New York are known to generally have a higher average number of insured patients than other states. For example, Massachusetts had 6.9\% uninsured in the general population in 2001 (the first year of the present study) and $4.1 \%$ in 2012, while New York had $13.8 \%$ uninsured in 2001 and $11.3 \%$ in 2012. In contrast, Texas had $22.4 \%$ uninsure in 2001 and $24.6 \%$ uninsured in $2012 .^{2}$

Thus, the baseline characteristics of a high rate of insurance in Massachusetts and New York inform the observation that both before and after the 2006 Massachusetts health care reform, the vast majority of patients in both states who underwent neurosurgical procedures were insured. In the current analysis, the "least insured" subgroup analyzed was the 2007 VP shunt subgroup, in which $3.5 \%$ of total cases were uninsured. The observed overall high rate of insurance both before and after reform also likely reflects the fact that the study probably has a high proportion of electively treated surgical patients as compared with, for example, a trauma population. Data from the Nationwide Inpatient Sample, for example, have shown that only $89.1 \%$ of patients with epidural hematoma were insured and $94.1 \%$ of patients with spine trauma were insured nationally, lower than the rates observed in this present report. ${ }^{1}$
Despite the fact that most patients were insured in both states at baseline in 2001, the time period following the Massachusetts health care reform implementation demonstrated a clear reduction in the already small number of uninsured patients in Massachusetts as compared with New York. One might speculate that ACA-style health care reform would have a greater impact on the rate of insured neurosurgical procedures in patient populations that were even more "uninsured" at baseline, such as in the trauma population or in states where a large percentage of patients are uninsured such as Texas. A future analysis that focuses on these populations would be an interesting area of follow-up study.

The question of impact of insurance status on procedure volume is an interesting one, especially in a world that remains largely fee for service. Do more insured patients equate to more procedures and fee-for-service activity? The present study suggests that in the already well-insured populations of Massachusetts and New York, health care reform did not appear to influence the volume of procedures performed. In the major categories of analysis (tumor, vascular, and shunts), procedure volumes were flat in both states. In contrast, spine surgery showed increased total volume in both states during the period of study, despite a trend of fewer uninsured cases in Massachusetts and more uninsured cases in New York. This latter observation of increasing volume for spine surgery is interesting. Although the increase did not achieve significance in Massachusetts, the increase in total volume in both states suggests that the drivers of increased volume relate less to insurance status and more to other factors.

The cost of our health care system continues to dominate national debates. This study provides a "glass half full, glass half empty" perspective on this issue. The optimists will note that increased insurance coverage for these populations did not generally lead to increases in total 
procedural volume, suggesting that we can improve social equity without increasing costs. The pessimists, however, may point out that for some procedures such as spine surgeries in the present study, total volumes continue to increase, thus making it hard to predict what the ultimate cost of health care reform may be. These trends should continue to be monitored in future studies.

http://thejns.org/doi/abs/10.3171/2015.11.JNS151576

\section{References}

1. McCutcheon BA, Chang DC, Marcus L, Gonda DD, Noorbakhsh A, Chen CC, et al: Treatment biases in traumatic neurosurgical care: a retrospective study of the Nationwide Inpatient Sample from 1998 to 2009. J Neurosurg 123:406414, 2015

2. United States Census Bureau: HIB-4. Health Insurance Coverage Status and Type of Coverage by State-All Persons: 1999 to 2012. Health Insurance Historical Tables - HIB Series. (https://www.census.gov/hhes/www/hlthins/ data/historical/HIB_tables.html) [Accessed December 30, 2015]

3. Villelli NW, Das R, Yan H, Huff W, Zou J, Barbaro NM: Impact of the 2006 Massachusetts health care insurance reform on neurosurgical procedures and patient insurance status. J Neurosurg [epub ahead of print March 11, 2016. DOI: $10.3171 / 2015.7 . J N S 15786]$

\section{Disclosures}

The authors report no conflict of interest.

\section{Response}

\section{Nicolas W. Villelli, MD, and Nicholas M. Barbaro, MD}

\section{Goodman Campbell Brain and Spine, Department of Neurological} Surgery, Indiana University School of Medicine, Indianapolis, Indiana

We appreciate and respect the editorial comments regarding our article. We believe this topic to be important to neurosurgery in a rapidly changing health care environment. The authors of the editorial make an important observation in that New York and Massachusetts have a lower percentage of uninsured population than the national average. Although this is true, we found it appropriate to use New York as a control because of the similarities in these two states, both geographically and economically. This choice allowed us to focus on the true impact of a mandated health insurance system on neurosurgery. With this approach, we have shown that insurance status does not appear to affect the number of procedures performed within the majority of neurosurgical subspecialties. The one subspecialty that showed a different trend in volume was spine. New York and Massachusetts showed a steady increase in spine procedure volume independent of insurance status or changes in health care policies. It is plausible that spine surgery may be affected differently than other neurosurgical subspecialties of neurosurgery, as it often treats less acute pathologies. Further research is needed to understand the impact of insurance status on spine surgery.

The comments by Carter and Chang related to epidural hematomas deserve further discussion. As mentioned in the editorial, $10 \%$ of national epidural hematomas occurred in uninsured individuals. This was used to argue that our study had a selection bias towards elective cases, as no procedure in Massachusetts exhibited such a high uninsured rate. But this, in fact, highlights one of the fundamental conclusions from our study. It would be unethical to not perform a life-saving procedure such as a craniotomy for an epidural hematoma, due to the patient's insurance status. Thus, if more trauma patients are insured, then there will be fewer uninsured trauma surgeries. As mentioned in the discussion section of our article, this observation was noted in orthopedic trauma surgeries after the Massachusetts policy change. ${ }^{1}$ It appears that trauma in a variety of surgical specialties can anticipate a decrease in uninsured surgeries after the passage of the ACA.

There is much subjective concern about the ACA and its impact on neurosurgery, but rarely have objective data been presented to support these claims. The data from Massachusetts provide an opportunity to better understand the impact of mandated insurance on a health care system. Our study shows factors other than insurance status will affect case volume in neurosurgery. The overall effect of such changes on a national level is still unclear. We agree with Carter and Chang that it is imperative to analyze national trends in neurosurgery in the coming years to better understand the full impact of the ACA on neurosurgery in the US.

\section{References}

1. Toussaint RJ, Bergeron SG, Weaver MJ, Tornetta P III, Vrahas MS, Harris MB: The effect of the Massachusetts healthcare reform on the uninsured rate of the orthopaedic trauma population. J Bone Joint Surg Am 96:e141, 2014 